\title{
The National Health Insurance, the decentralised clinical training platform, and specialist outreach
}

\author{
R I Caldwell, ${ }^{1} \mathrm{BSc}$ (Med), MB ChB, FCP (SA), FRCP (Lond); C Aldous, ${ }^{1} \mathrm{PhD}$ \\ School of Clinical Medicine, Department of Internal Medicine, College of Health Sciences, University of KwaZulu-Natal, Pietermaritzburg, \\ South Africa
}

Corresponding author: R I Caldwell (ric@caldwells.co.za)

\begin{abstract}
According to the Constitution of South Africa (SA), citizens living in remote areas are entitled to the same level of healthcare as those with access to tertiary hospitals. Specialist outreach has been shown to achieve this. When SA's National Health Services Commission convened (1942 - 1944), Gluckman summarised: 'Where the need is greatest the supply of hospitals is least.' Primary healthcare (PHC) characterised the Kark's Pholela Health Centre and was highly regarded. Although PHC underpins National Health Insurance (NHI) planning, both preventive and curative healthcare are needed. The KwaZulu-Natal (KZN) provincial Department of Health and the University of KZN College of Health Sciences' 5-year plan for a decentralised clinical teaching platform (DCTP) is ambitious, requiring optimum co-operation between health department and university. Reservations can be addressed through sustained specialist outreach. Above all, the patient must be the chief beneficiary. The NHI and DCTP overlap with specialist outreach, but cannot do without it.
\end{abstract}

S Afr Med J 2017;107(1):39-40. DOI:10.7196/SAMJ.2017.v107i1.12008

According to the Constitution of South Africa (SA), an impoverished citizen living in a rural area is entitled to the same level of specialist healthcare as an employed person living in a city with ready access to a tertiary hospital. A proven way to accomplish this is through multifaceted specialist outreach, as shown in numerous international studies, particularly those from Australia, Canada, and SA. ${ }^{[1-6]}$

The 1971 inverse care law stated: 'Availability of medical care is inversely related to the needs of the population. ${ }^{[}[7]$ When the 1942 - 1944 SA National Health Services Commission convened, Gluckman summarised: 'Where the need is greatest the supply of hospitals is least,' referring to impoverished remote rural areas. ${ }^{[8]}$ The Commission had the task of reporting on 'the provision of an organised National Health Service, in conformity with the modern conception of "Health" for all sections of the people of the Union of South Africa. ${ }^{[8,9]}$ In 1940, the concept of primary healthcare (PHC) and community health centres (CHCs) was pioneered by Drs Sidney and Emily Kark at Pholela in rural Natal, and was highly regarded as 'a continuous process by which primary care is provided to a defined community on the basis of its assessed health needs. ${ }^{\text {' }}{ }^{10,11]}$

Because of the emphasis on PHC, this philosophy is included in strategies for the SA National Health Insurance (NHI) and in the decentralised clinical teaching platform (DCTP)/community-based training in a PHC model (CBTPHCM). Such principles are well founded, but to achieve a comprehensive system they must go hand-in-hand with curative healthcare, with a specialist component. ${ }^{[12-14]}$ Neglecting the financing of tertiary services soon after democracy led to near closure of Cape Town's Red Cross War Memorial Children's Hospital, for example. ${ }^{[15]}$

Even at the time of the Commission, reservations were expressed about the adequacy of the Pholela/Kark health strategy, and major advances in medicine during the past 80 years are a sine qua non of modern healthcare. ${ }^{[16-18]}$ The national health plan was never launched and consequently CHCs did not survive in SA. ${ }^{[16]}$ Nonetheless, the minister of health, Dr Aaron Motsoaledi, is a proponent of Gluckman's principles; therefore it is imperative to keep these in the forefront of any discussion on public health matters.

\section{Discussion}

In line with NHI philosophy, the KZN provincial Department of Health (DoH) and the University of KwaZulu-Natal (UKZN) College of Health Sciences have an ambitious CBTPHCM/DCTP 5-year plan: piecemeal social engineering in its most well-intentioned manner, perhaps ${ }^{[19,20]}$ The programme could achieve the following: embodying PHC principles; doubling the 1st-year $\mathrm{MB} \mathrm{ChB}$ intake at UKZN in 2017 to 512 students; mechanisms for the retention of doctors in rural areas; training of under- and postgraduates away from the major centres; and registrars available to staff these sites.

Reservations include provision of three specialists in each discipline for every site when it is problematic to fill posts at regional hospitals, as an unfulfilled consultant-registrar-undergraduate ratio (1:3:12) would be contrary to Health Professions Council of SA (HPCSA) regulations. ${ }^{[19]}$ Although studies have suggested that doctors originating from rural areas are more likely to practise in such areas, this is not guaranteed. ${ }^{[21-23]}$ Specialist outreach experience in KZN suggests a different situation, i.e. foreign doctors comprise a large proportion of district hospital staff. ${ }^{[3,4]}$ Given current militant attitudes, would an undergraduate body not feel that they are being engineered into a situation contrary to the tendency towards globalisation?

Apart from optimum co-operation between the DoH and UKZN, DCTP requires the contribution of specialist outreach alongside focused PHC development. Specialist outreach serves disadvantaged patients in remote areas. ${ }^{[1-6]}$ Infrastructure in KZN includes a competent transport provider, i.e. the Red Cross Air Mercy Service - if their contract is renewed. ${ }^{[3-5]}$ This programme already provides specialists from the major disciplines to district hospitals on a regular monthly basis, encompassing both a teaching and a clinical service. These consultants continue in their accustomed role as specialists in urban communities, and yet provide specialist outreach.

The DCTP envisages a service to its patients, and under- and postgraduate training, dovetailing best with specialist outreach; indeed, it cannot do without it. Outreach consultants increase the 
specialist presence on site, improve service delivery to patients, establish liaison between peripheral and central hospitals, and provide under- and postgraduate teaching. This may obviate or postpone physical referral and transport, as appropriate treatment can be recommended and initiated at the base hospital, or it may facilitate rapid acceptance and transfer of patients when it is apparent that urgent specialist intervention is needed. For 'in-between' degrees of urgency, there may be an opportunity for patients to be assessed by a specialist during the regular monthly outreach visit.

However, the only reference to peripheral specialist contribution in the NHI White Paper of early 2016 is in the form of 'district specialists. ${ }^{\text {[24] }}$ These are limited to four disciplines: paediatrics, obstetrics, anaesthetics and family medicine, whose consultants travel to hospitals within a particular health district. Therefore, if excluded from formal policy in the NHI, long-established multifaceted specialist outreach programmes of proven ability to 'deliver the goods' might come to an end, denying the sustainability that is a prerequisite for the full benefit of such outreach.

Above all, there has to be assurance that the patient is the chief beneficiary in the three-way process involving patient, health department and university. The sheer necessity is that the NHI must include specialist outreach. Consequently, both will be compatible with the DCTP, as the NHI is based on the principles of PHC and CHCs.

\section{Conclusion}

Specialist outreach is a proven strategy worldwide and has an indispensable role to play in both the DCTP and the NHI. These have much to be commended, but there are serious reservations that need to be researched and answered. ${ }^{[25]}$ Preventive health is vital - but so is curative medicine. Certainly, as Prof. Dan Ncayiyana stated in 1994 in support of Karkian philosophy, 'there is no need to rediscover the wheel.[26] Equally, one must be sure not to throw the baby out with the bathwater. ${ }^{[3,4,27]}$

1. Gruen RL, Bailie RS. Specialist clinicsin remote Australian aboriginal communities: Where rock art meets rocket science. J Health Serv Res Policy 2004;9(Suppl 2):61. http://dx.doi.org/10.1258/1355819042349844 2. Gruen RL, Weeramanthri TS, Knight SE, Bailie RS. Specialist outreach clinics in primary care and rura hospital settings. Cochrane Database Syst Rev 2004;(1):CD003798. http://dx.doi.org/10.1002/14651858. CD003798.pub2

3. Caldwell RI, Gaede BM, Aldous C. Description of an internal medicine outreach consultant appointment in western KwaZulu-Natal, South Africa, 2007 to mid-2014. S Afr Med J 2015;105(5):353 356. http://dx.doi.org/10.7196/SAMJ.9173
4. Caldwell RI, Gaede BM, Aldous C. The value of internal medicine outreach in rural KwaZulu-Natal. S Afr Med J 2016:106(3):259-262. http://dx.doi.org/10.7196/SAMJ.2016.v106i3.10278

5. Gaede BM, McKerrow NH. Outreach programme: Consultant visits to rural hospitals. CME . Gaede BM, McKer
2011;29(2):57-58.

2011;29(2):57-58.
6. Schoevers J, Jenkins L. Factors influencing specialist outreach and support services to rural populations 6. Schoevers J, Jenkins L. Factors influencing specialist outreach and support services to rural populations
in the Eden and Central Karoo districts of the Western Cape. Afr J Primary Health Care Fam Med 2015;7(1). http://dx.doi.org/10.4102/phcfm.v7i1.750

Tudor Hart J. The inverse care law. Lancet 1971;1(7696):405-412

8. Marks S. Reflections on the 1944 National Health Services Commission: A response to Bill Freund and Anne Digby on the Gluckman Commission. S Afr Historical J 2014;66(1):169-187. http://dx.doi.org/1 0.1080/02582473.2014.890331

9. Gluckman $\mathrm{H}$. The provision of an organized national health service for all sections of the people of the Union of South Africa, 1942 - 1944. Report of the National Health Services Commission. Pretoria: Government Printer, 1944

10. Tollman S. The Pholela Health Centre - the origins of community-oriented primary health care (COPC). An appreciation of the work of Sidney and Emily Kark. S Afr Med J 1994;84(10):653-658.

11. Mullan F, Epstein L. Community-oriented primary care: New relevance in a changing world. Am J 1. Mullan F, Epstein L. Community-oriented primary care: New relevance in a cha
Public Health 2002;92(11):1748-1755. http://dx.doi.org/10.2105/AJPH.92.11.1748

12. Kautzkyi K, Tollman SM. A Perspective on Primary Health Care in South Africa. South African Health Review. Durban: Health Systems Trust, 2008.

13. Schaayi N, Sanders D. International Perspective on Primary Health Care Over the Past 30 Years. Perspective on Primary Health Care in South Africa. Durban: Health Systems Trust, 2008.

14. Coovadia H, Jewkes R, Barron P, Sanders D, McIntyre D. Health in South Africa 1. The health and health system of South Africa: Historical roots of current public health challenges. Lancet 2009;374(9692):817-834. http://dx.doi.org/10.1016/S0140-6736(09)60951-X

15. Baleta A. Children's hospital has to shut doors. http://www.iol.co.za/news/south-africa/childrenshospital-has-to-shut-doors-18619 (accessed 14 July 2016).

16. Digby A. Evidence, encounters and effects of South Africa's reforming Gluckman National Health Services Commission, 1942 - 1944. S Afr Historical J 2012;64(2):187-205. http://dx.doi.org/10.1080/0 2582473.2011 .651623

17. Freund B. The South African developmental state and the first attempt to create a national health system: Another look at the Gluckman Commission of 1942 - 1944. S Afr Historical J 2012:64(2):170186. http://dx.doi.org/10.1080/02582473.2011.640708

18. Digby A. Debating the Gluckman Commission: A rejoinder. S Afr Historical J 2014;66(3):588-592. Digby A. Debating the Gluckman Commission:
http://dx.doi.org/10.1080/02582473.2014.932951

19. KwaZulu-Natal Department of Health and University of KwaZulu-Natal. Community based training in a primary health care model. Durban: KZN DoH, 2013.

20. Popper K. The Open Society and its Enemies. Princeton, NJ: Princeton University Press, 1971.

21. Wilson NW, Couper ID, de Vries E, Reid S, Fish T, Marais BJ. A critical review of interventions to redress the inequitable distribution of healthcare professionals to rural and remote areas. Rural Remote Health 2009;9(2):1060-1081

22. Muzigaba M, Naidoo K, Ross A, Nadesan-Reddy N, Pillay S. Predictors of site choice and eventual learning experiences in a decentralised training programme designed to prepare medical students for careers in underserved areas in South Africa. Afr J Health Professions Educ 2016;8(1 Suppl 1):92-98. http://dx.doi.org/10.7196/AJHPE.2016.v8i1.74

23. Grobler L, Marais BJ, Mabunda SA, Marindi PN, Reuter H, Volmink J. Interventions for increasing the proportion of health professionals practising in rural and other underserved areas. Cochrane Database Syst Rev 2009;(1):CD005314. http://dx.doi.org/10.1002/14651858.CD005314.pub2

24. National Department of Health. National Health Insurance for South Africa. Towards Universal Health Coverage. Version 40. Pretoria: NDoH, 2015.

25. Tollman SM, Pick WM. Roots, shoots, but too little fruit: Assessing the contribution of COPC in South Tollman SM, Pick WM. Roots, shoots, but too
Africa. Am J Public Health 2002;92(11):1726.

26. Ncayiyana D. The Pholela PHC model - no need to rediscover the wheel. S Afr Med J 1994:84(10):91.

27. Phillips $\mathrm{H}$. The return of the Pholela experiment. Medical history and primary health care in post-apartheid South Africa. Am J Publ Health 2014;104(10):1873. http://dx.doi.org/10.2105/ AJPH.2014.302136

Accepted 19 September 2016. 